\title{
An Improved Approach to Measuring Sexual Dimorphism in Snakes: Morphological Variation in the Bahamian Racer (Cubophis vudii vudii)
}

Scott Johnson ${ }^{1}$ and William K. Hayes ${ }^{2}$

${ }^{1}$ The Bahamas National Trust, East Bay Street, P.O. Box N 4105, Nassau, The Bahamas (sjohnson@bnt.bs)

${ }^{2}$ Department of Earth and Biological Sciences, Loma Linda University, Loma Linda, California 92350, USA

\begin{abstract}
Sexual dimorphism in animals exists in many forms, including overall size difference between the sexes (sexual size dimorphism, SSD) and size and structural differences in body components (sexual body component dimorphism, SBCD). Studies of sexual dimorphism seek to determine whether dimorphic traits result from sexual selection, natural selection, or non-adaptive processes. Characterizing sexual dimorphism depends on identifying an unbiased character for overall body size, which can then be used to assess both SSD and SBCD. Most studies of snakes use snoutvent length (SVL) for this purpose, but SVL may itself be dimorphic. In this study, we examined SSD and SBCD in three island populations of the Bahamian Racer (Cubophis vudii vudii). Discriminant function analysis (DFA) showed that head width (females wider) and tail length (males longer) best discriminated between the sexes, and total length provided the least discrimination. Linear models using total length as the least-biased measure for overall size revealed an absence of SSD, but SBCD existed for head size (width $8.9 \%$ greater in females, length similar), trunk length (4.3\% longer in females), and tail length (9.8\% longer in males). Linear models also revealed differences among island populations for total length (New Providence $<$ Eleuthera $=$ Allen Cay) and head length (Allen Cay $<$ Eleuthera $<$ New Providence), but not head width or tail length. Extent of SBCD varied depending on choice of character to control for overall body size, with total length yielding the most female-biased values, and geometric mean, principal component 1 (PC1) of a principal components analysis, and SVL providing increasingly more male-biased values, respectively. Body condition was statistically similar for the two sexes and three seasons (spring, summer-fall, winter), but the moderate and large effect sizes, respectively, suggest that females were heavier than males, and both sexes were heaviest in spring. Females, which represented 64.9 of all snakes, suffered injuries disproportionately to males $(19.7 \%$ and $3.1 \%$, respectively), but no differences in sex ratio or frequency of injury existed among the island populations. Collectively, these findings illustrate the utility of using DFA and other approaches (geometric mean, PC1) to identify a relatively unbiased reference character for overall body size and suggest that sexual and natural selection interact to shape the morphology of these snakes.
\end{abstract}

Sexual dimorphism in animals has been an area of great Ointerest for researchers for decades, and has bolstered our knowledge of how topics such as resource competition, sexual selection, and natural selection have played important roles in shaping the behavioral and morphological differences between male and female animals (Hedrick and Temeles 1989; Bonnet et al. 1998, 2001; Vincent et al. 2004). For example, the longer and/or larger body size in many female animals might be selected because it can support a larger clutch size, thus increasing reproductive success (Shine 1994; Cox et al. 2007). In some species of herbivorous lizards and snakes that engage in vigorous battles over females, males tend to be larger than females and their larger body size could be a result of intrasexual selection to increase their chances of overpowering rival males (Carothers 1984; Shine 1994; Schuett 1997; McElligott et al. 2001).

Sexual dimorphism is not restricted to overall body size (sexual size dimorphism, SSD). Selection can also affect individual body components of male and female animals (sexual body component dimorphism, SBCD). The longer limbs of male Steppe Tortoises (Testudo horsfieldii), for example, might assist them in quickly righting themselves after being turned over during battles with other males (Bonnet et al. 2001), and the longer tails in many species of male reptiles 
could have been selected to house longer copulatory organs that give them a mating advantage (King 1989; Shine et al. 1999; Kratochvíl et al. 2003). The larger heads of some species of male iguanid lizards could help them win battles against rival males (Carothers 1984).

Although sexual selection often is cited for many differences seen in male and female animals, it can be difficult to isolate from other important factors that can affect the development of differences between the sexes (Cooper and Vitt 1989; Monnet and Cherry 2002). Ecological forces such as procurement of food or escaping predators can mask traits attributed to sexual selection (Bonnet et al. 2001; Brown et al. 2017). Differences in longevity of the sexes, as in Sidewinders (Crotalus cerastes; Reiserer 2016), or age structure, as in anurans (Monnet and Cherry 2002), can also account for differences in sizes of males and females. Reproductive costs can differentially affect body components, with selection favoring females having longer abdomens to accommodate larger clutches (Pincheira-Donoso and Hunt 2017), and even females of "flying lizards" having larger wing membranes than males to support flight while gravid (Shine et al. 1998). Shine (1991), nevertheless, suggested that only when differences in body size are inconsistent with what would be expected due to sexual selection can ecological causes be attributed to dimorphism.

Characterizing sexual dimorphism depends on identifying an unbiased character for overall body size, which can then be used to assess both SSD and SBCD. Differential scaling of individual body components can make the choice of this character challenging (Fox et al. 2015). Researchers studying lizards and snakes, for example, almost invariably compare the head size of males and females relative to snoutvent length (SVL) or sometimes trunk length. However, SVL itself can be a dimorphic character (Braña 1996; Cochran 2019; Kratochvil et al. 2003; Olsson et al. 2002; Scharf and Miri 2013). Snout-vent length is comprised largely of the trunk; thus, if SVL is affected by selection favoring a larger volume for total clutch, then positive allometric growth of the female abdomen would ensure that all other body components, including the head, are male-biased in size at an equivalent SVL (Braña 1996; Cochran 2019; Kratochvil et al. 2003; Olsson et al. 2002; Scharf and Miri 2013).

Several approaches can be used to identify or derive an unbiased measure of overall body size. First, one could consider a single character that corresponds to overall size, such as body mass, but nutritional state and reproductive condition can substantially bias this measure, especially in ectotherms. Second, one could use a discriminant function analysis (DFA) to identify the least dimorphic character, which has been used for scorpions (Fox 2018; Fox et al. 2015). A third, more widely used approach involves use of the first eigenvalue (PC1) of a principal-components analysis (PCA), which typi-

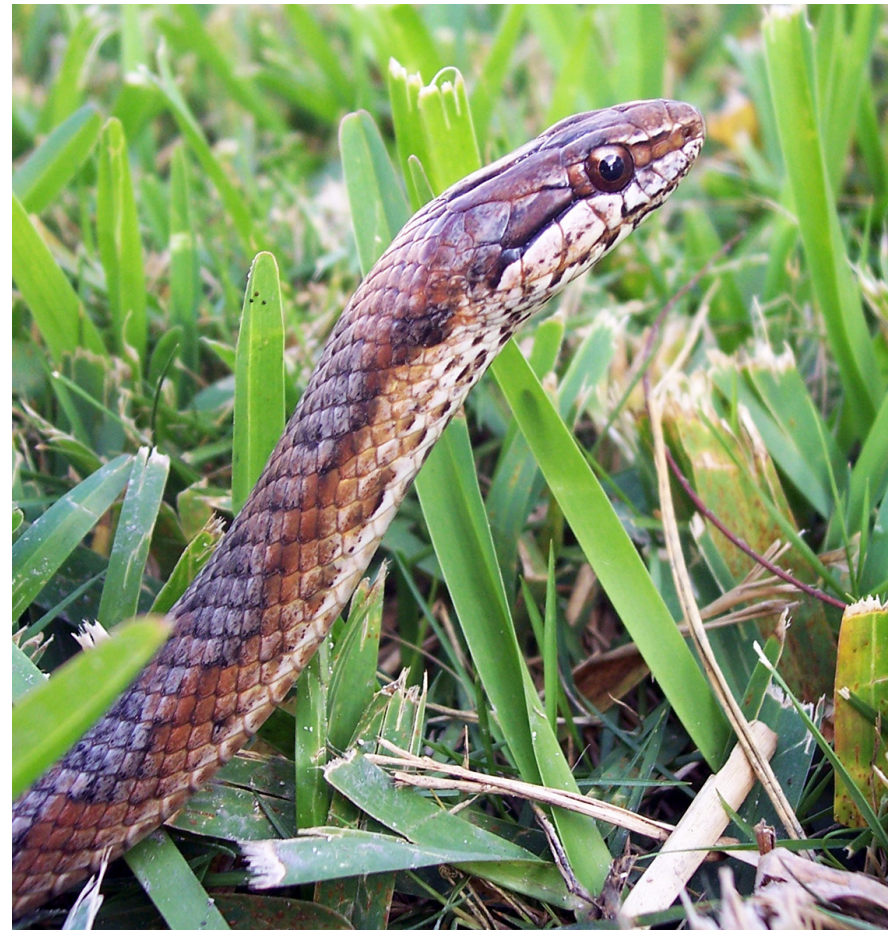

Fig. 1. A Bahamian Racer (Cubophis vudii vudii) from New Providence. Photograph by Scott Johnson.

cally encompasses overall size, with the additional orthogonal components generally representing shape (e.g., Bookstein et al. 1985; Jolicoeur 1963; Somers 1986). A fourth method is to use the geometric mean of multiple measurements $\left(\mathrm{n}^{\text {th }}\right.$ root of the product of $\mathrm{n}$ variables), which effectively removes shape to express overall size (Mosimann 1970; Mosimann and James 1979).

In this paper, we relied primarily on DFA to examine SSD and SBCD in the Bahamian Racer (Cubophis vudii vudii; Fig. 1), a West Indian xenodontine that is endemic to The Bahamas. We chose this as our primary approach to test its utility for the first time ever, we believe, in snakes. We also compared the use of the least-biased measure selected by this approach — total length - to results from using geometric mean, PC1, and SVL as alternative measures (covariates) for overall body size. By examining specimens from three islands (Fig. 2), we further assess whether differences in body size and dimorphism exist among those populations and fluctuate across seasons, and whether the sex ratio differs among islands. Finally, we describe injuries sustained by snakes, and test whether differences in frequencies of injuries exist between sexes or among the islands.

\section{Methods}

Measurements. - One of us (SJ) captured 116 specimens of C. v. vudii on three islands (Fig. 1): Allen Cay of the

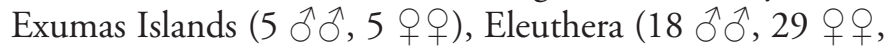




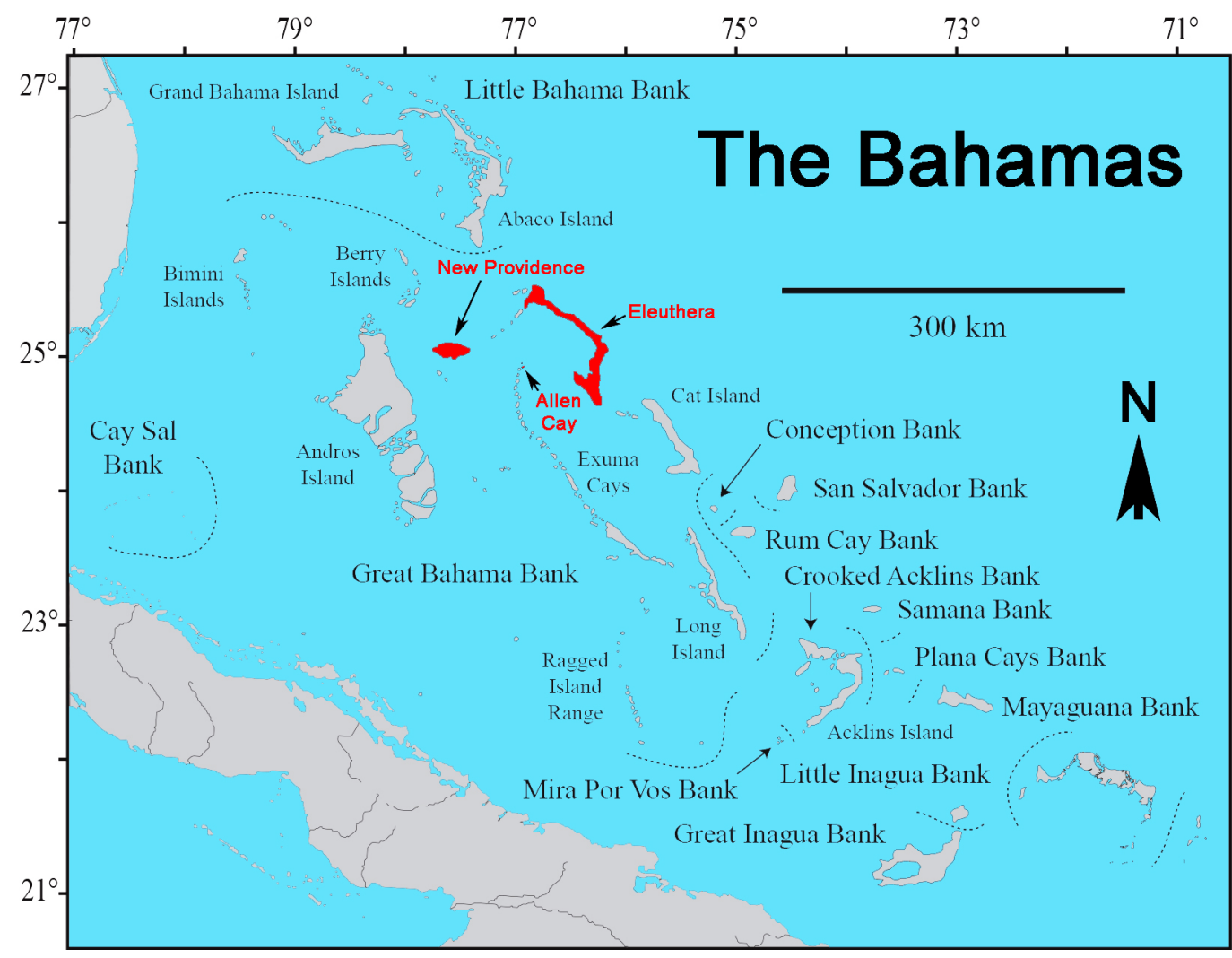

Fig. 2. Map of The Bahamas, highlighting the islands on which the three populations of Bahamian Racers (Cubophis vudii vudii) were studied.

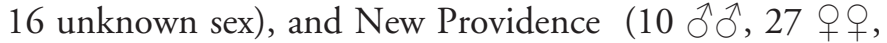
6 unknown sex). Snakes were captured year-round during multiple trips to each island, but we categorized seasons as spring (March-May), summer and fall (June-November, pooled due to the small sample size for summer), and winter (December-February). We omitted from morphological analyses all females captured in June due to assumed oviposition that month (juveniles first appear in August) and its effect on body condition. The following measurements (to the nearest $1 \mathrm{~mm}$ ) were obtained using a tape measure on live snakes restrained by hand on a flat surface: head length (HL, tip of snout to back of jaw) and width (HW, broadest part of the skull), SVL, and tail length (TaL). We subsequently calculated trunk length $(\mathrm{TrL}=\mathrm{SVL}-$ head length), total length $(\mathrm{ToL}=\mathrm{SVL}+\mathrm{TaL})$, and the geometric mean of the four independent measurements (HL, HW, TrL, TaL). Snake mass was measured to the nearest gram using a 100 -g capacity scale (Pesola Präzisionswaagen AG, Schindellegi, Switzerland). Snakes were sexed using lubricated (K-Y personal lubricant or Vaseline) snake-sexing probes (Big Apple Herpetological, Hauppauge, New York, USA) cleaned with 70\% isopropyl alcohol between uses. Females probed at a depth less than the width of the tail (2-3 subcaudals), whereas males probed deeper than the width of the tail ( $>4$ subcaudals). Sex and mass were not determined for some animals when equipment was unavailable in the field. We also recorded injuries, including scars and missing portions of tails. We excluded from body-size analyses all snakes that were missing a portion of their tails. Because no details are available for minimum reproductive size in the species, we used all snakes in our analyses, which likely included snakes of both subadult and adult age classes.

Analyses.-We conducted statistical tests using SPSS 13.0 for Windows (Statistical Package for the Social Sciences, Inc., Chicago, Illinois, 2004), with $\alpha=0.05$. We screened data prior to analyses to remove multivariate outliers based on Mahalanobis distances (Tabachnick and Fidell 2013) and to ensure that parametric assumptions were met (unless indicated otherwise). Because all morphological measures were linearly related and curve-fitting options (exponential, logarithmic, power, and quadratic transformations) failed to improve pairwise coefficients of determination $\left(r^{2}\right)$, we applied no transformations to the mensural data.

We used general linear models (Tabachnick and Fidell 2013) to assess morphological relationships, including analysis of variance (ANOVA), analysis of covariance (ANCOVA), multiple analysis of variance (MANOVA), DFA, and PCA. For the DFA, we included HL, HW, TrL, TaL, SVL, and ToL; we used SPSS defaults with prior probabilities set to all groups equally; we included leave-one-out classification to cross-validate accuracy of group assignments; and we considered classification success relative to random as an effect size. 
For the PCA, we generated principal component 1 (PC1) regression scores for each snake using standardized data (for HL, HW, TrL, TaL), a correlation matrix, unrotated factors, and SPSS defaults. For the ANOVA, ANCOVA, and MANOVA models, we computed eta-squared $\left(\eta^{2}\right)$, partial $\eta^{2}$, or multivariate partial $\eta^{2}$ as effect sizes, depending on the number of variables in a model, with values of $\sim 0.01$, $\sim 0.06$, and $>0.14$ loosely deemed small, moderate, and large effects, respectively (Cohen 1988). To evaluate sex ratios and injuries, we relied on binomial probability, with effect size indicated by percent difference from expected (Green and Salkind 2005), and on chi-square and Fisher's exact tests, with Cramer's $V$ and phi $(\varphi)$ values, respectively, of $\sim 0.1$, $\sim 0.3$, and $>0.5$ loosely regarded as small, moderate, and large effects (Cohen 1988).

We computed Lovich and Gibbons (1992) dimorphism index values for SSD and SBCD based on mean values from ANOVAs and on estimated marginal means from ANCOVAs, respectively. With this index, 0 means absence of sex differences; positive values indicate female-biased dimorphism; negative values indicate male-biased dimorphism; and values multiplied by 100 provide the percent difference relative to the smaller sex, which we report because doing so is more intuitive and avoids values with excessive decimal places. We could not compute an index value for SSD using PC1 because of the scaling effect associated with extraction.

\section{Results}

Sex differentiation and distinction between measures of SSD and $S B C D$.- We used a DFA model to identify which variables contributed most and least to morphological differentiation of the sexes. The DFA, obtained from $32 \hat{\jmath} \overline{0}$ and 54 우우 pooled from all three islands (after removal of one multivariate outlier), yielded a highly significant model (Wilks' $\Lambda=0.76, \chi^{2}=22.58, \mathrm{df}=4, \mathrm{P}<0.001$, canonical correlation for the single function $=0.491$ ). The model included four variables, as two were excluded due to multicollinearity (Table 1). Classification success was $74.4 \%$ (males $81.3 \%$, females $70.4 \%$ ) for original cases, and $72.1 \%$ (males $75.0 \%$, females $70.4 \%$ ) for cross-validated cases. Thus, males and females could be differentiated with much better success than expected by chance $(50.0 \%)$. Based on joint consideration of standardized canonical discriminant function coefficients and structure matrix coefficients (Table 1), HW (females wider) and $\mathrm{TaL}$ (males longer) best discriminated between the sexes, and ToL provided the least discrimination. Accordingly, ToL can be justified as the least-biased character (among this particular character set) for overall body size.

We analyzed SSD and SBCD in the following sections based largely on these results. We assessed SSD using two characters (ToL [all populations] and mass [Eleuthera snakes only]) and evaluated SBCD for the four body components
Table 1. Results of discriminant function analysis (DFA) for sex differentiation in the Bahamian Racer (Cubophis vudii vudii) based on morphological measures. *Excluded from DFA due to multicollinearity (low tolerance values).

\begin{tabular}{lcc} 
Measure & $\begin{array}{c}\text { Standardized } \\
\text { Canonical Discriminant } \\
\text { Function Coefficients }\end{array}$ & $\begin{array}{c}\text { Structure } \\
\text { Matrix Coefficients }\end{array}$ \\
\hline Head width & 1.179 & 0.475 \\
\hline Tail length & -0.930 & 0.474 \\
\hline Head length & 0.292 & 0.380 \\
\hline Snout-vent length* & & 0.234 \\
\hline Trunk length & -0.496 & 0.226 \\
\hline Total length* & & 0.014 \\
\hline
\end{tabular}

(HL, HW, TrL, TaL) using ToL as the reference character (covariate) for overall body size. We omitted SVL from analysis because it combined two body components and is collinear with trunk length $(r=1.000)$.

Sexual size dimorphism.-Because sufficient data for mass were available only from Eleuthera, we restricted analyses involving mass to this population. A MANCOVA model using the combined dependent variable of ToL and mass revealed no difference between the sexes (Wilks' $\Lambda=0.98$, $F_{2,24}=0.20, \mathrm{P}=0.82$, multivariate $\eta^{2}=0.017 ; 8$ ते $\widehat{\partial}, 19$ + P ; no outliers removed). Follow-up univariate ANOVAs confirmed the absence of sexual dimorphism on Eleuthera for both ToL $\left(F_{1,25}=0.21, \mathrm{P}=0.65, \eta^{2}=0.008\right)$ and mass $\left(F_{1,25}\right.$ $=0.02, \mathrm{P}=0.90, \eta^{2}=0.001$ ).

A $2 \times 3$ ANOVA (sex $\times$ island) model for ToL, which included snakes from all three islands (Allen Cay, $5 \widehat{\partial} \widehat{\partial}, 4$

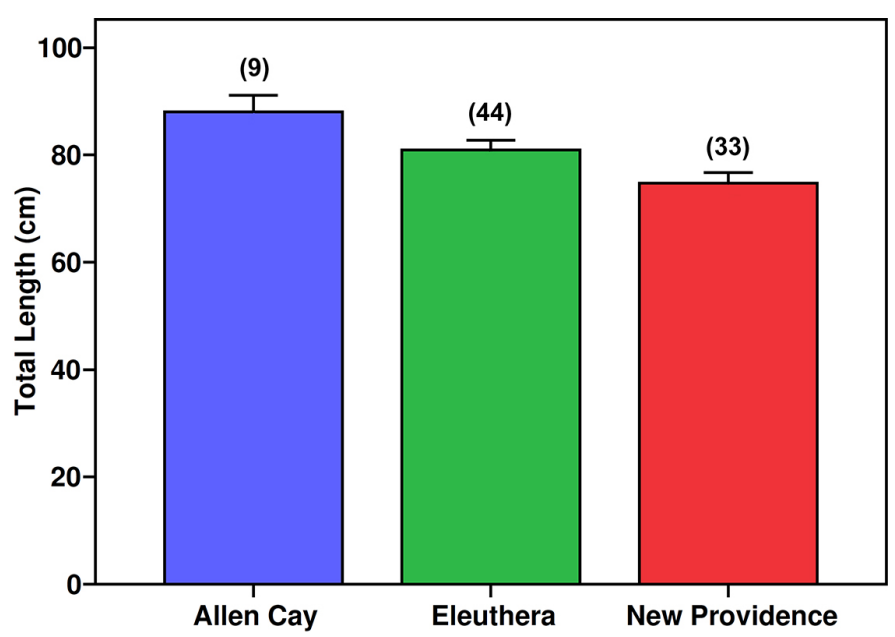

Fig. 3. Overall body-size (total length) comparisons among island populations of the Bahamian Racer (Cubophis vudii vudit). Sample sizes are indicated parenthetically, and sexes were pooled due to absence of sexual size dimorphism. Differences were significant $(\mathrm{P}=0.001)$, with pairwise comparisons indicating New Providence $<$ Eleuthera $=$ Allen Cay in total length. 


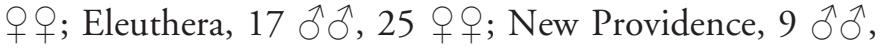
24 우; two multivariate outliers removed), failed to meet the assumption of homoscedasticity, and no transformations (logarithmic, rank) improved the situation. Because ANOVA is generally robust to failed assumptions (Tabachnick and Fidell 2013), we went ahead and analyzed the original data. The ANOVA yielded no interaction between island and sex $\left(F_{2,78}=0.95, \mathrm{P}=0.39\right.$, partial $\left.\eta^{2}=0.024\right)$ and no difference between the sexes $\left(F_{1,78}=0.07, \mathrm{P}=0.79\right.$, partial $\eta^{2}=$ $0.001)$. However, snake length differed significantly among the islands $\left(F_{2,78}=8.08, \mathrm{P}=0.001\right.$, partial $\left.\eta^{2}=0.172\right)$, with Tukey's multiple comparisons (mean $\pm 1 \mathrm{SE}$ ) indicating New Providence $(74.7 \pm 1.98 \mathrm{~cm})<$ Eleuthera $(82.3 \pm 1.62 \mathrm{~cm})=$ Allen Cay $(88.0 \pm 3.11 \mathrm{~cm})$ in length (Fig. 3).

Matching $2 \times 3$ ANOVAs for alternative measures of overall body size (geometric mean, PC1, SVL, and TrL) yielded conclusions similar to those obtained from ToL: absence of SSD and comparable island differences (though weaker for geometric mean $[\mathrm{P}=0.053]$ and $\mathrm{PC} 1[\mathrm{P}=0.047])$. Lovich and Gibbons (1992) index values for SSD were 0.38 for ToL, 2.92 for geometric mean, 5.44 for SVL, and 5.36 for TrL.

Sexual body component dimorphism.-To reduce attribute space and alleviate the need for a covariate as a reference character for overall body size (ToL) in ANCOVA models, we separately regressed each of the four body component variables (HL, HW, TrL, TaL) against ToL and then analyzed the residuals as the dependent variables in ANOVA models. Use of residuals was further advantageous because, when sexual differences in a body component exist, they generally diverge with snake size, resulting in non-homogenous regression slopes for the sexes, violating a key assumption of ANCOVA. We

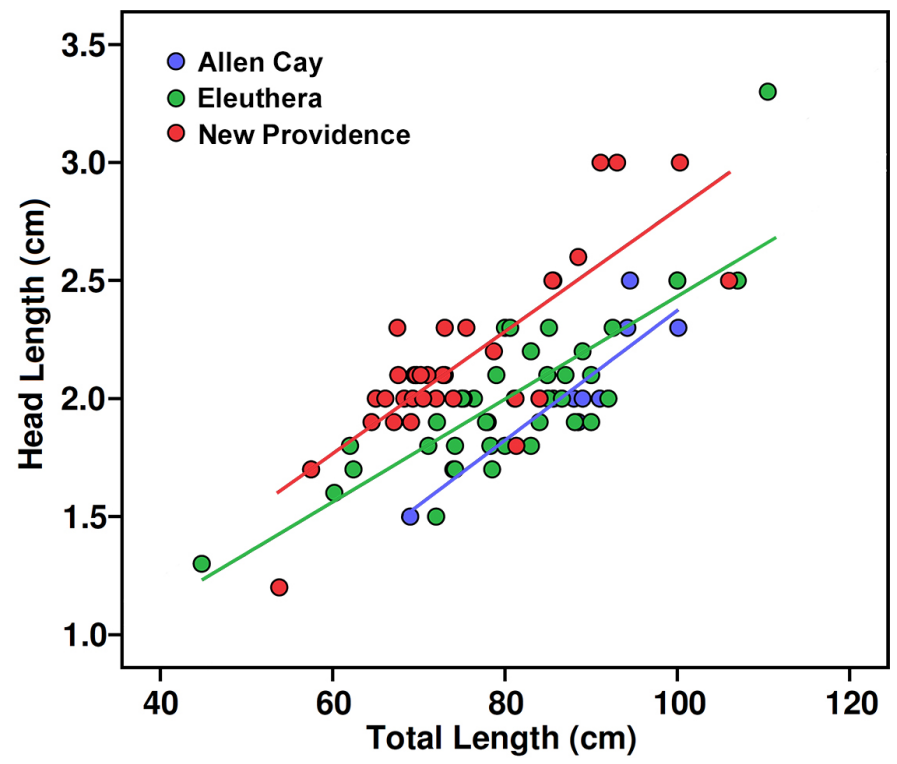

Fig. 4. Relative head length of island populations of Bahamian Racers (Cubophis vudii vudi). Differences were significant $(\mathrm{P}<0.001)$, with rank order of Allen Cay < Eleuthera $<$ New Providence $(n=9,42$, and 33, respectively). Males $(n=32)$ and females $(n=54)$ had similar head lengths. nevertheless used ANCOVA models with ToL as a covariate to compute estimated marginal means for sex and for islands when significant. All of the following analyses were based on the aforementioned DFA sample of 86 snakes.

To examine head-size variation, we used a $2 \times 3(\operatorname{sex} \times$ island) MANOVA to evaluate the combined dependent variable of head length residuals and HW residuals (i.e., relative head length and width). Significant differences existed between the sexes (Wilks' $\Lambda=0.81, F_{2,79}=9.56, \mathrm{P}<0.001$, multivariate partial $\eta^{2}=0.195$ ) and among the islands (Wilks' $\Lambda=0.72, F_{4,158}=7.04, \mathrm{P}<0.001$, multivariate partial $\eta^{2}=$ 0.151 ), with no interaction between sexes and islands (Wilks' $\Lambda=0.96, F_{4,158}=0.84, \mathrm{P}=0.50$, multivariate partial $\eta^{2}=$ $0.021)$. Follow-up univariate $2 \times 3$ ANOVAs revealed contrasting patterns in the two head size measures. Relative head length was similar for males and females (estimated marginal means of $2.0 \pm 0.04$ and $2.1 \pm 0.04 \mathrm{~cm}$, respectively, at 79.3 $\mathrm{cm} \mathrm{ToL} ; F_{1,80}=2.77, \mathrm{P}=0.10$, partial $\left.\eta^{2}=0.033\right)$, but differed among the islands $\left(F_{2,80}=13.95, \mathrm{P}<0.001\right.$, partial $\eta^{2}$ $=0.259$; Fig. 4), with no interaction $\left(F_{2,80}=0.02, \mathrm{P}=0.99\right.$, partial $\left.\eta^{2}<0.001\right)$. Rank order of relative head length was Allen Cay $(1.8 \pm 0.07 \mathrm{~cm})<$ Eleuthera $(2.0 \pm 0.03 \mathrm{~cm})<\mathrm{New}$ Providence $(2.2 \pm 0.04 \mathrm{~cm})$. Tukey's multiple comparisons indicated that only the $21.1 \%$ difference between Allen Cay and New Providence was significant. Relative head width, in contrast, was similar among the islands $\left(F_{2,80}=0.10, \mathrm{P}\right.$ $=0.908$, partial $\left.\eta^{2}=0.002\right)$, but differed between the sexes $\left(F_{1,80}=19.35, \mathrm{P}<0.001\right.$, partial $\eta^{2}=0.195$; Fig. $)$, with no interaction $\left(F_{2,80}=1.53, \mathrm{P}=0.22\right.$, partial $\left.\eta^{2}=0.037\right)$. Heads averaged $12.0 \%$ wider in females $(1.1 \pm 0.02 \mathrm{~cm})$ compared to males $(1.0 \pm 0.02 \mathrm{~cm})$.

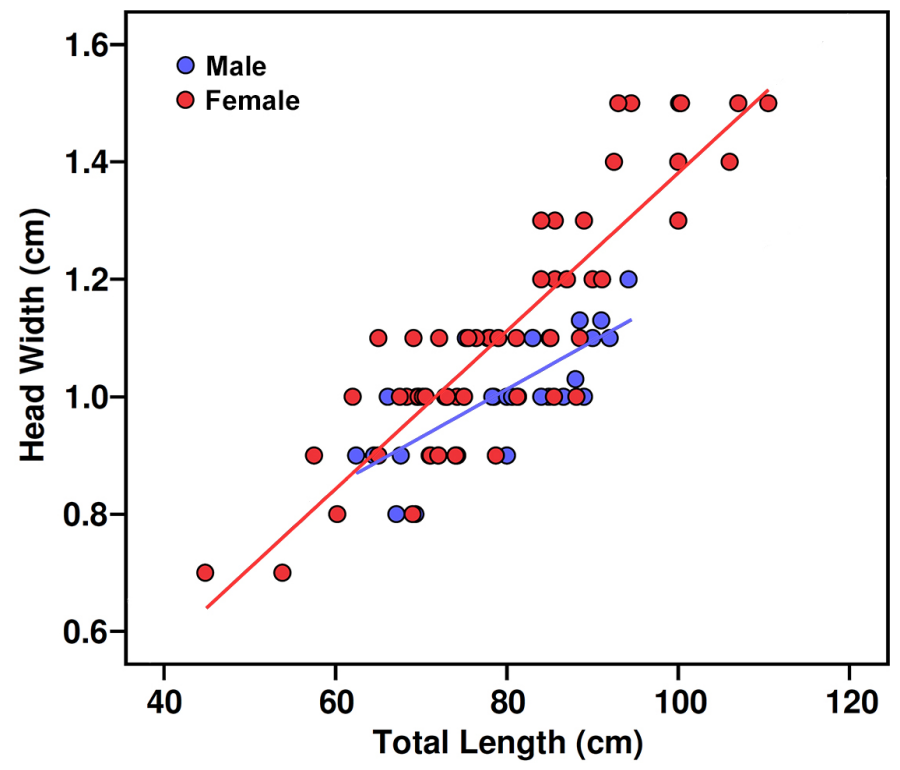

Fig. 5. Relative head width of male and female Bahamian Racers (Cubophis vudii vudii). Differences were significant $(\mathrm{P}<0.001)$, with females $(\mathrm{n}=$ 54 ) having wider heads than males $(\mathrm{n}=32)$. No island differences existed. 


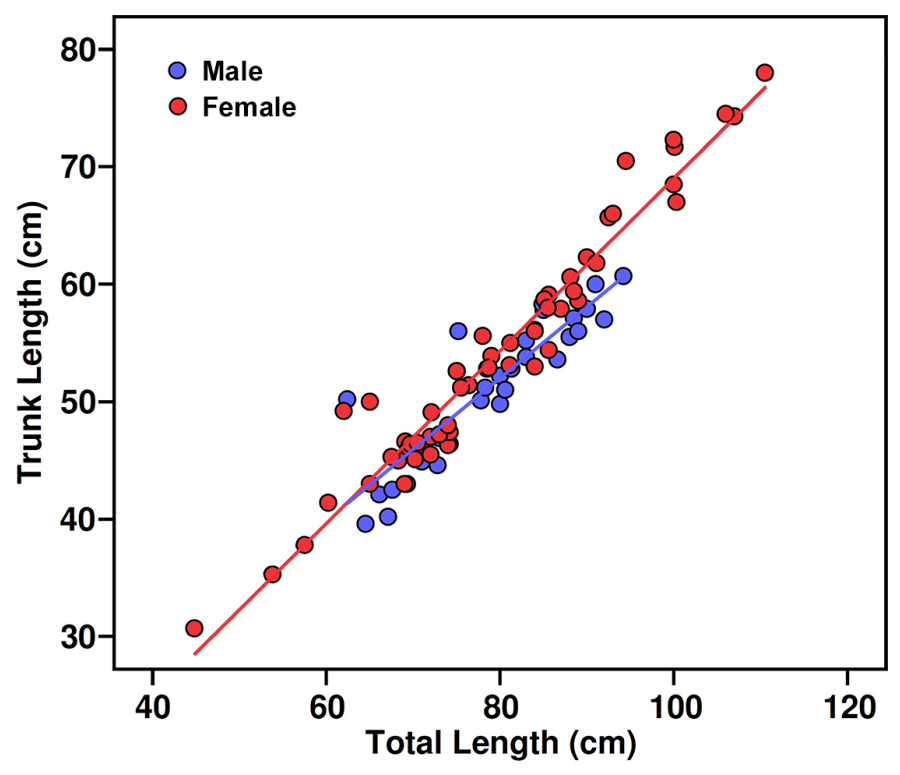

Fig. 6. Relative trunk length of male and female Bahamian Racers (Cubophis vudii vudii). Differences were significant $(\mathrm{P}<0.001)$, with females $(\mathrm{n}=54)$ having longer trunks than males $(\mathrm{n}=32)$. No island differences existed.

To examine trunk-length variation, we subjected the trunk-length residuals to a $2 \times 3$ (sex $\times$ island) ANOVA. Relative trunk length was similar among the islands $\left(F_{2,80}=\right.$ 2.68, $\mathrm{P}=0.075$, partial $\left.\eta^{2}=0.063\right)$, but differed significantly between the sexes $\left(F_{1,80}=22.13, \mathrm{P}<0.001\right.$, partial $\left.\eta^{2}=0.217\right)$, with no interaction of sex and island $\left(F_{2,80}=2.61, \mathrm{P}=0.080\right.$, partial $\eta^{2}=0.061$ ). Trunks averaged $6.5 \%$ longer in females $(54.4 \pm 0.49 \mathrm{~cm}$ at $79.3 \mathrm{~cm}$ ToL; $67.7 \pm 0.03 \%$ of ToL) than males $(51.1 \pm 0.52 \mathrm{~cm} ; 65.1 \pm 0.04 \%$ of ToL; Fig. 6).

To examine tail-length variation, we similarly subjected the tail-length residuals to a $2 \times 3$ (sex $\times$ island) ANOVA. Relative tail length was similar among the islands $\left(F_{2,80}=\right.$ $1.74, \mathrm{P}=0.182$, partial $\left.\eta^{2}=0.042\right)$, but differed significantly between the sexes $\left(F_{1,80}=22.19, \mathrm{P}<0.001\right.$, partial $\eta^{2}$ $=0.217)$, with no interaction of sex and island $\left(F_{2,80}=2.46\right.$, $\mathrm{P}=0.092$, partial $\left.\eta^{2}=0.058\right)$. Tails averaged $15.0 \%$ longer in males $(26.3 \pm 0.53 \mathrm{~cm}$ at $79.3 \mathrm{~cm}$ ToL; $32.4 \pm 0.04 \%$ of $\mathrm{ToL})$ than females $(22.8 \pm 0.50 \mathrm{~cm} ; 29.6 \pm 0.03 \%$ of ToL; Fig. 7).

To compare SBCD outcomes based on five different covariates for overall body size, we used the same ANCOVA approach to compute estimated marginal means using four additional covariates (geometric mean, PC1, SVL, and trunk length). Dimorphism among the four body components varied depending on which covariate was used (Fig. 8), except that SVL and trunk length yielded identical values. Head length dimorphism was absent regardless of covariate; female-biased HW dimorphism existed regardless of covariate; female-biased trunk length dimorphism was detected using all covariates except SVL and trunk length; and malebiased tail length was evident with all five covariates. Bias

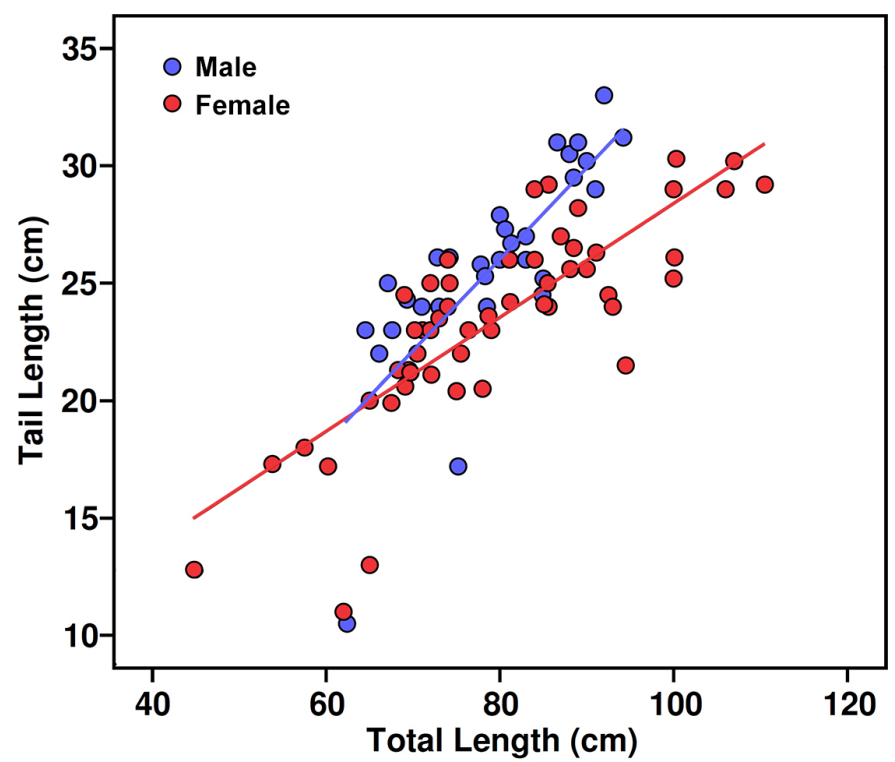

Fig. 7. Relative tail length of male and female Bahamian Racers (Cubophis vudii vudii). Differences were significant $(\mathrm{P}<0.001)$, with males $(\mathrm{n}=32)$ having longer tails than females $(\mathrm{n}=54)$. No island differences existed.

of covariates toward a given sex was consistent across body components, with ToL yielding the most female-biased values, and geometric mean, PC1, and SVL ( $\approx$ trunk length)

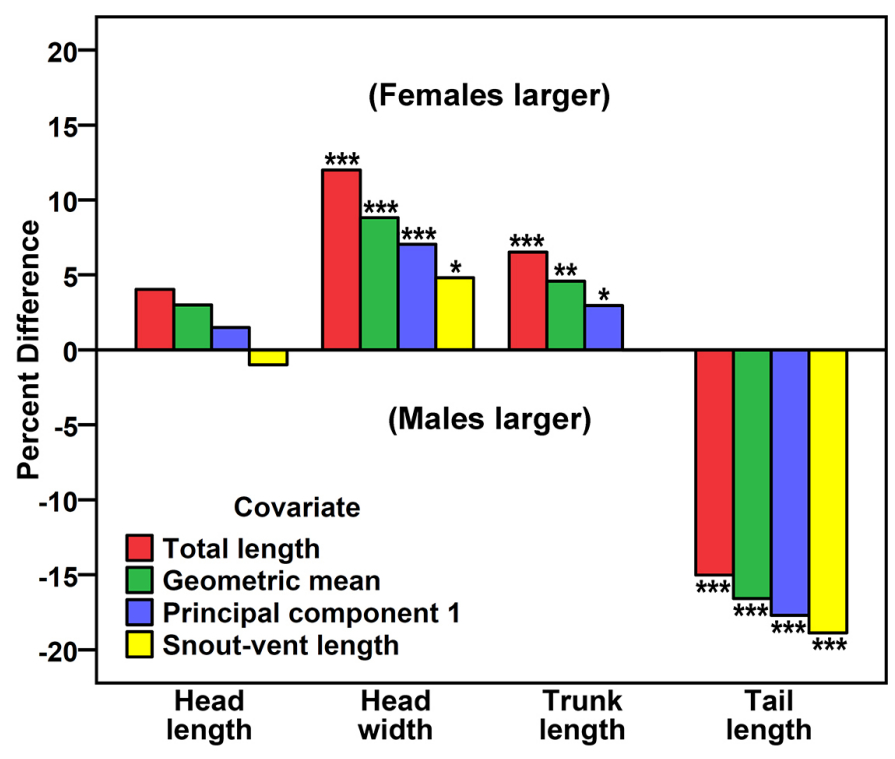

Fig. 8. Percent difference in size between male and female Bahamian Racers (Cubophis vudii vudii) relative to the smaller sex for four body components: head length, head width, trunk length, and tail length ( $\mathrm{n}=32$ males, 54 females). Interpretation and magnitude of sexual body component dimorphism depended on reference character (covariate) used to control for overall body size, with increasing male bias in order of total length, geometric mean, principal component 1 (PC1) from a principal components analysis, and snout-vent length (SVL; trunk length yielded values identical to SVL). Values correspond to the Lovich and Gibbons (1992) dimorphism index, with positive values indicating females larger and negative values indicating males larger. Significance of sex differences in analysis of covariance (ANCOVA) models: ${ }^{*} \mathrm{P}<0.05,{ }^{* *} \mathrm{P}<0.01,{ }^{* * *} \mathrm{P}<0.001$. 
providing increasingly more male-biased values, respectively. The majority of ANCOVA models had non-homogenous regression slopes resulting from increasing dimorphism with increasing body size, but slopes were always homogenous statistically when SVL was the covariate.

Body condition.-To test for sex differences and seasonal variation in body condition, we used the residuals of mass against ToL in a $3 \times 2$ (season $\times$ sex) ANOVA with type IV sum-of-squares due to missing data in one cell. Body condition was similar between sexes $\left(F_{1,23}=1.81, \mathrm{P}=0.191\right.$, partial $\left.\eta^{2}=0.073\right)$ and among seasons $\left(F_{2,23}=2.47, \mathrm{P}=0.106\right.$, partial $\left.\eta^{2}=0.177\right)$. No interaction between sex and season $\left(F_{1,23}\right.$ $=0.001, \mathrm{P}=0.977$, partial $\left.\eta^{2}<0.001\right)$ was evident, but this might reflect the small sample size. The moderate effect of sex suggests that females have on average better overall body condition than males, and the large effect of season suggests that body condition is greatest in spring (Fig. 9).

Sex ratios.-A $2 \times 3$ (sex $\times$ island) chi-square test suggested that sex ratios were similar among the three populations (Allen Cay, 50.0\% male, $\mathrm{n}=10$; Eleuthera, 38.3\% male, $\mathrm{n}=47$; New Providence, $27.0 \%$ male, $\mathrm{n}=37 ; \chi^{2}=$ $2.24, \mathrm{df}=2$, asymptotic $\mathrm{P}=0.33$, Cramer's $V=0.155)$. After pooling data across populations $(\mathrm{n}=94)$, the sex ratio for all snakes was clearly female-biased, with females $(64.9 \%)$ outnumbering males $(35.1 \%)$ nearly two to one (binomial $\mathrm{P}=$ $0.005,14.9 \%$ difference from expected value of $50.0 \%$ ).

Injuries.-A one-sample chi-square test revealed no difference in frequency of injuries among the three islands (Allen Cay, $0.0 \%$ of 10 ; Eleuthera, $16.1 \%$ of 62 ; New Providence,

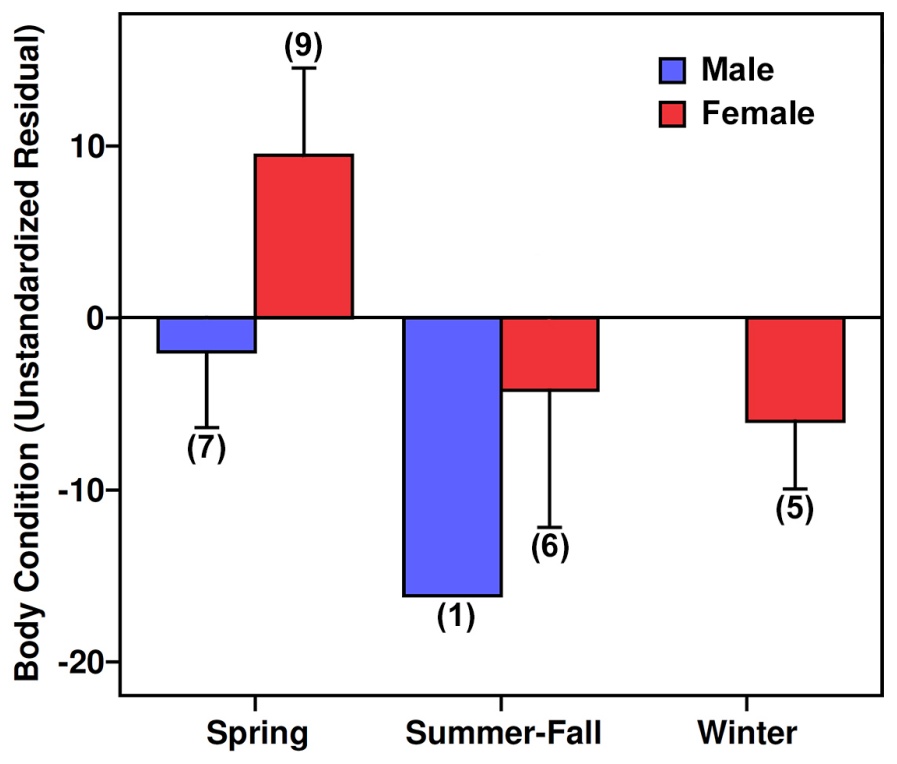

Fig. 9. Seasonal comparisons of body condition between male and female Bahamian Racers (Cubophis vudii vudii) among islands. Relatively medium and large effect sizes, respectively, suggest that body condition was potentially female-biased (partial $\eta^{2}=0.073$ ) and greater in spring than in other seasons (partial $\eta^{2}=0.177$ ). Sample sizes are provided within parentheses.
$11.6 \%$ of $43 ; \chi^{2}=2.10, \mathrm{df}=2$, asymptotic $\mathrm{P}=0.35$, Cramer's $V=0.135)$. However, females suffered more frequent injuries than males $(19.7 \%$ of 61 and $3.1 \%$ of 32 , respectively; Fisher's exact test, $\mathrm{P}=0.031, \varphi=0.227$ ). Injuries included those to the trunk $(\mathrm{n}=2)$, missing portions of the tail $(\mathrm{n}=$ $7)$, scars on the tail $(n=4)$, and two individuals with unusual bulges in the cloaca.

\section{Discussion}

In this paper, our primary goal was to apply a DFA approach to identify a relatively unbiased character for overall body size in the Bahamian Racer and use that character (ToL) to test for SSD and SBCD. This approach allowed us to better assess dimorphism compared to the conventional use of SVL, which is flawed because SVL in this species appears to be a femalebiased character, likely due to fecundity selection acting on trunk (abdomen) length. Our results revealed a complete absence of SSD in the three populations examined, but three of four body components (HW, TrL, and TaL) exhibited unambiguous SBCD. Secondarily, we also explored sex and population differences in body size and proportions, body condition, sex ratio, and injuries to the trunks and tails of racers.

Overall body size and sexual size dimorphism.-The most important and novel finding of this study is that DFA can be used to identify a relatively unbiased measure of overall body size (ToL in this study) in at least some snakes. None of the three island populations of the Bahamian Racer, nor the combined groups, exhibited SSD. This was true regardless of the measure used for overall body size. The fact that ToL and geometric mean yielded similar results (SSD indices of 0.28 and 2.92, respectively) gives us confidence that ToL provided a reliable measure of SSD. Female bias was greater for SVL and TrL (SSD index >5), suggesting that other species with a greater difference between the sexes might give discordant interpretations of SSD depending on the measure used, resulting in, for example, a significant difference in SVL or $\operatorname{TrL}$ but not ToL or geometric mean.

Absence of SSD in C. v. vudii contrasted with two other West Indian xenodontine snakes: male-biased SSD in Anegadan Racers (Borikenophis portoricensis anegadae; Barun et al. 2007) and female-biased SSD in Antiguan Racers (Alsophis antiguae; Daltry et al. 2001). In many species of snakes in which conspecifics engage in combat, SSD might be advantageous because it could increase mating success (Shine 1994; Schuett 1997). The Bahamian Racer, however, is not known to engage in combat, so the similar overall body sizes might not have been as greatly influenced by sexual selection as in some other species. The lack of SSD in the Bahamian Racer might be attributable to other factors, such as natural selection, which could have standardized body size as a result of resource procurement (Bonnet et al. 2001). On some islands 
where largely arboreal anoline lizards are the only major food source, large body size could hinder successful prey capture.

Bahamian Racers on Allen Cay were the largest among the three islands (though statistically similar to those on Eleuthera). Island differences could result from differential exposure to native predators (e.g., crabs, birds); to invasive predators such as Black Rats (Rattus rattus) and domestic or feral cats (Felis catus) and dogs (Canis lupus familiaris); and/or to human development. The Allen Cays comprise a cluster of uninhabited islands $32 \mathrm{~km}$ southeast of New Providence and are the most northern cays in the Exuma chain. This isolation and lack of invasive predators (although mice [Mus musculus] were present until recent eradication; Alifano et al. 2014) might have allowed individuals in this population to attain larger sizes than those on other islands.

Sexual body component dimorphism.-Use of ToL as a covariate to control for overall size revealed SBCD in three body components of Bahamian Racers: female-biased HL and TrL, and male-biased TaL. Geometric mean and PC1 as covariates yielded similar results, adding confidence to our use of ToL, whereas SVL as a covariate gave weak HW dimorphism and complete absence of TrL dimorphism (Fig. 8). Cochran (2019), who examined SSD and SBCD in the Southwestern Speckled Rattlesnake (Crotalus pyrrhus), similarly found increasing male bias in SBCD with geometric mean, PC1, and SVL, respectively, when using these measures as covariates for overall body size. Although the DFA approach worked well in our study, ToL was non-dimorphic in large part because female-biased $\mathrm{TrL}$ differences were balanced by male-biased TaL differences, which may not be the case for other snake species. Male ToL averaged $79.2 \mathrm{~cm}$ compared to $79.4 \mathrm{~cm}$ for females, with female trunks $2.4 \mathrm{~cm}$ longer and male tails $2.3 \mathrm{~cm}$ longer.

Presence of SBCD in Bahamian Racers could result from a combination of natural selection (including survival selection and fecundity selection) and/or sexual selection. Survival selection might have acted on females resulting in wider heads that could facilitate the handling of larger prey items and exploiting a wider range of food resources, thereby decreasing competition with conspecific males (Vincent et al. 2004). Fecundity selection presumably acted on female bodies by increasing trunk length to support larger clutch sizes and, secondarily, decreasing tail length to compensate (King 1989). Sexual selection likely favored longer tails in males to accommodate hemipenes and retractor muscles that facilitate reproduction (King 1989), as longer tails in male Red-sided Gartersnakes (Thamnophis sirtalis parietalis) have been associated with greater reproductive success (Shine et al. 1999). Bahamian Racers are unusual in that, similar to many natricine snakes (Shine 2000), males have shorter trunks but possess a greater number of ventral scales than females (169-181 and 159-166, respectively; Powell 2014). Number of ventrals corresponds to number of vertebrae (Shine 2000). Although HL dimorphism was absent, we can only speculate that island differences in HL have resulted from natural selection arising from different habitat structure and/or prey availability.

Body condition.-Sample sizes were small, but effect sizes were sufficient to suggest that several trends might exist (Fig. 9). Female racers appear to have greater mass than males, at least during the spring, when the former store fat in preparation for reproduction. Barun et al. (2007) measured B. p. anegadae in autumn, when females also had greater mass per unit length than males. The effect of season on body condition in our snakes was stronger, suggesting post-parturient females in summer/fall and in winter have less mass than females in spring. Similar trends were reported in the Bahamian Rock Iguana (Cyclura rileyi rilevi), in which females were heavier than males, but only during the reproductive season, and both sexes were heaviest in the spring and leanest in the fall (Carter and Hayes 2004). It remains unclear whether all adult female racers reproduce annually, which would likely influence body-size differences in spring.

Sex ratio.-Although island sex ratios were relatively similar, we found a significant skew overall with females outnumbering males by almost 2:1. This could result from sampling bias if females are more active or forage in more open habitats, and therefore are more likely to be caught than males. Female bias could also result from higher mortality in males, although females experienced higher levels of injury (see next section). Skewed sex ratios resulting from differential mortality have been reported in several species of snakes (Shine et al. 2001; Wang and Tu 2003; Patten et al. 2009). Skewed sex ratios favoring females can also occur when inbreeding is frequent (Shine and Bull 1977), in which case we would expect the skew to be greater on smaller islands (e.g., Allen Cay), which we did not see. Clearly, further study is necessary to shed more light on this bias.

Injuries.-Thirteen percent of the snakes had injuries that included scars on trunks and tails, and missing portions of tails. Injury frequency was similar among islands, but disproportionate in females ( $19.7 \%$ compared to $3.1 \%$ in males) for reasons unclear to us. This might reflect higher levels of female activity or differential habitat use that increases exposure to predators; greater vulnerability to attacks, perhaps when gravid; or greater ability to survive attacks. Most injuries $(86.7 \%)$ were to the tails, but tail injuries were scarce (6.1\% of all snakes, excluding the scars and bulges) compared to reports from other West Indian xenodontines (70\% in $B$. p. anegadae, Barun et al. 2007; 42\% in A. antiguae, Daltry et al. 2001).

Tail damage could have been caused by several factors, including failed predation by other animals. Barun et al. (2007) reported that many B. p. anegadae had scars on the tail and posterior portions of the body, with larger individuals 
having a higher frequency. They concluded that scars were probably caused by failed predation attempts by Soldier Crabs (Coenobita clypeatus). Damage to tails might also reflect failed predation attempts or parental defense by rats and birds. Bahama Mockingbirds (Mimus gundlachii) and Northern Mockingbirds (Mimus polyglottos) defending their nesting territories have been observed pecking at the tails of Bahamian Racers, which include small birds in their diet (Schwartz and Henderson 1991). Invasive rodents such as rats can also damage tails. Hayes et al. (2012) indicated that Bahamian Rock Iguanas experienced higher rates of tail injuries on islands with rat populations, so the assumption that rodents might attack a snake for food or to defend its young is plausible. Bulges in or near the cloaca in two specimens might have been caused by parasites or infections.

\section{Conclusions}

Using the right approach to properly analyze SSD and SBCD is crucial to understanding and interpreting sexual dimorphism. Because SVL is comprised largely of TrL in snakes, which can be subject to fecundity selection, SVL should not be used as a measure of overall body size. Although we show that a DFA approach can be utilized to derive a more neutral measure than SVL (or TrL), we learned after completing our initial analyses that geometric mean has properties that should make it the most suitable character for overall body size in all taxa for which multiple measurements are obtained (Mosimann 1970; Mosimann and James 1979). Although PC1 should also be a better alternative to SVL, it's more cumbersome than geometric mean to compute and cannot be used to derive the Lovich and Gibbons (1992) index for SSD due to the scaling effect associated with extraction.

In the Bahamian Racer, both sexual and natural selection likely influence the morphological differences observed between the sexes. Still, more research needs to be done on this poorly studied species. Additional details regarding habitat use, home range, activity levels, diet, and predationparticularly predation by invasive species like rats-would shed additional light on the morphology and ecology of this endemic snake in The Bahamas.

\section{Acknowledgments}

We thank Joe Wunderle, Dave Ewert, Robert Henderson, Joe Wasilewski, Ancilleno Davis, and Gail Woon for positive critiques of earlier drafts of this manuscript. We also thank Gerad Fox and Chip Cochran for extensive discussions on how to measure dimorphism.

\section{Literature Cited}

Alifano, A., P. Moore, W. Mackin, J. Iverson, R. Griffiths, B. Fabres, W. Jolley, and N.D. Holmes. 2014. The power of partnerships: Eradicating invasive mice from Allen Cay, The Bahamas, pp. 78-82. In: R.M. Timm, and J.M. O'Brian (eds.), Proceedings of the Twenty-sixth Vertebrate Pest Conference. Division of Agriculture and Natural Resources, University of California, Davis, California.
Barun, A., G. Perry, R.W. Henderson, and R. Powell. 2007. Alsophis portoricensis anegadae (Squamata: Colubridae): Morphometric characteristics, activity patterns, and habitat use. Copeia 2007: 93-100.

Bookstein, F.L., B. Chernoff, R.L. Elder, Jr., J.M. Humphries, G.R. Smith, and R.F. Strauss. 1985. Morphometrics in Evolutionary Biology. The Academy of Natural Sciences of Philadelphia, Philadelphia, Pennsylvania.

Bonnet, X., R. Shine, G. Naulleau, and M. Vacher-Vallas. 1998. Sexual dimorphism in snakes: different reproductive roles favour different body plans. Proceedings of the Royal Society of London B: Biological Sciences 265: 179-183.

Bonnet, X., F. Lagarde, B.T. Henen, J. Corbin, K.A. Nagy, G. Naulleau, K. Balhoul, O. Chastel, A. Legrand, and R. Cambag. 2001. Sexual dimorphism in Steppe Tortoises (Testudo horsfieldii): influence of the environment and sexual selection on body shape and mobility. Biological Journal of the Linnean Society 72: 357-372.

Braña F. 1996. Sexual dimorphism in lacertid lizards: male head increase vs female abdomen increase? Oikos 75: 511-523.

Brown, G.P., T.R. Madsen, and R. Shine. 2017. Resource availability and sexual size dimorphism: differential effects of prey abundance on the growth rates of tropical snakes. Functional Ecology 31: 1592-1599.

Carothers, J.H. 1984. Sexual selection and sexual dimorphism in some herbivorous lizards. The American Naturalist 124: 244-254.

Carter, R.L. and W.K. Hayes. 2004. Conservation of an endangered Bahamian iguana. II. Morphological variation and conservation recommendations, pp. 258-273. In: A.C. Alberts, R.L. Carter, W.K. Hayes, and E.P. Martins (eds.), Iguanas: Biology and Conservation. University of California Press, Berkeley, California.

Cochran, C. 2019. Variation in morphology, diet, and venom composition in Crotalus pyrrhus. Unpublished Ph.D. dissertation, Loma Linda University, Loma Linda, California.

Cohen, J. 1988. Statistical Power Analysis for the Behavioral Sciences. 2nd ed. Lawrence Erlbaum Associates, Inc., Hillsdale, New Jersey.

Cooper, W.E. and L.J. Vitt. 1989. Sexual dimorphism of head and body size in an iguanid lizard: Paradoxical results. The American Naturalist 133: 729-735.

Cox, R.M., M.A. Butler, and H.B. John-Alder. 2007. The evolution of sexual size dimorphism in reptiles, pp. 38-49. In: D.J. Fairbain, W.U. Blanckenhorn, and T. Székely (eds.), Sex, Size \& Gender Roles: Evolutionary Studies of Sexual Size Dimorphism. Oxford University Press, Oxford, United Kingdom.

Daltry, J.C., Q. Bloxam, G. Cooper, M.L. Day, J. Hartley, M. Henry, K. Lindsay, and B.E. Smith. 2001. Five years of conserving the 'world's rarest snake', the Antiguan Racer Alsophis antiguae. Oryx 35: 119-127.

Fox, G.A. 2018. The design of complex weapons systems in scorpions: Sexual, ontogenetic, and interspecific variation. Unpublished Ph.D. dissertation, Loma Linda University, Loma Linda, California.

Fox G.A., A.M. Cooper, and W.K. Hayes. 2015. The dilemma of choosing a reference character for measuring sexual size dimorphism, sexual body component dimorphism, and character scaling: Cryptic dimorphism and allometry in the scorpion Hadrurus arizonensis. PLoS One 10: e0120392.

Green, S.B. and N.J. Salkind. 2005. Using SPSS for Windows and Macintosh: Analyzing and Understanding Data. 4th ed. Pearson Prentice Hall, Upper Saddle River, New Jersey.

Hayes, W.K., J.B. Iverson, C.R. Knapp, and R.L. Carter. 2012. Do invasive rodents impact endangered insular iguana populations? Biodiversity and Conservation 21: $1893-1899$.

Hedrick, A.V. and E.J. Temeles. 1989. The evolution of sexual dimorphism in animals: Hypotheses and tests. Trends in Ecology and Evolution 4: 136-138.

Jolicoeur, P. 1963. The multivariate generalization of the allometry equation. Biometrics 19: 497-499.

King, R.B. 1989. Sexual dimorphism in snake tail length: sexual selection, natural selection, or morphological constraint? Biological Journal of the Linnean Society 38: 133-154.

Kratochvil, L., M. Fokt, I. Rehak, and D. Frynta. 2003. Misinterpretation of character scaling: a tale of sexual dimorphism in body shape of common lizards. Canadian Journal of Zoology 81: 112-117.

Lovich, J.E. and J.W. Gibbons. 1992. A review of techniques for quantifying sexual size dimorphism. Growth, Development and Aging 56: 269-281.

McElligott, A.G., M.P. Gammell, H.C. Harty, D.R. Paini, D.T. Murphy, J.T. Walsh, and T.J. Hayden. 2001. Sexual size dimorphism in Fallow Deer (Dama dama): Do larger, heavier males gain greater mating success? Behavioral Ecology and Sociobiology 49: 266-272. 
Monnet, J.M. and M.I. Cherry. 2002. Sexual size dimorphism in anurans. Proceedings of the Royal Society of London. Series B: Biological Sciences 269: 2301-2307.

Mosimann J. 1970. Size allometry: Size and shape variables with characterizations of the lognormal and generalized gamma distributions. Journal of the American Statistical Association 65: 930-945.

Mosimann, J.E. and F.C. James. 1979. New statistical methods for allometry with application to Florida Red-winged Blackbirds. Evolution 33: 444-459.

Olsson, M., R. Shine, E. Wapstra, B. Ujvari, and T. Madsen. 2002. Sexual dimorphism in lizard body shape: The roles of sexual selection and fecundity selection. Evolution 56: 1538-1542.

Patten, T.J., J.D. Fawcett, and D.D. Fogell. 2009. Natural history of the Western Massasauga (Sistrurus catenatus tergeminus) in Nebraska. Journal of Kansas Herpetology 30: 13-20.

Pincheira Donoso, D. and J. Hunt. 2017. Fecundity selection theory: Concepts and evidence. Biological Reviews 92: 341-356.

Powell, R. 2014. Cubophis vudii. Catalogue of American Amphibians and Reptiles 903: $1-15$.

Reiserer, R.S. 2016. The rattle: A window on rattlesnake life histories, pp. 301342. In: G.W. Schuett, M.J. Feldner, C.F. Smith, and R.S. Reiserer (eds.), Rattlesnakes of Arizona, Volume 2: Conservation, Behavior, Venom, and Evolution. Eco Publishing, Rodeo, New Mexico.

Scharf, I. and S. Miri. 2013. Sexual dimorphism of heads and abdomens: different approaches to "being large" in female and male lizards. Biological Journal of the Linnean Society 110: 665-674.

Schuett, G.W. 1997. Body size and agonistic experience affect dominance and mating success in male copperheads. Animal Behavior 54: 213-224.

Schwartz, A. and R.W. Henderson 1991. Amphibians and Reptiles of the West Indies:
Descriptions, Distributions, and Natural History. University Press of Florida, Gainesville, Florida.

Shine, R. 1991. Intersexual dietary divergence and the evolution of sexual dimorphism in snakes. The American Naturalist 138: 103-122.

Shine, R. 1994. Sexual size dimorphism in snakes revisited. Copeia 1994: 326-346.

Shine, R. 2000. Vertebral numbers in male and female snakes: The roles of natural, sexual and fecundity selection. Journal of Evolutionary Biology 13: 455-465.

Shine, R. and J.J. Bull. 1977. Skewed sex ratios in snakes. Copeia 1977: 228-234.

Shine, R., S. Keogh, P. Doughty, and H. Giragossyan. 1998. Costs of reproduction and the evolution of sexual dimorphism in a "flying lizard" Draco melanopogon (Agamidae). Journal of Zoology 246: 203-213.

Shine, R., M.P. LeMaster, I.T. Moore, M.M. Olsson, and R.T. Mason. 2001. Bumpus in the snake den: Effects of sex, size, and body condition on mortality of red sided garter snakes. Evolution 55: 598-604.

Shine, R., M.M. Olsson, I.T. Moore, M.P. LeMaster, and R.T. Mason. 1999. Why do male snakes have longer tails than females? Proceedings of the Royal Society of London B: Biological Sciences 266: 2147-2151.

Somers, K.M. 1986. Multivariate allometry and removal of size with principal components analysis. Systematic Zoology 35: 359-368.

Tabachnick, B.G. and L.S. Fidell. 2013. Using Multivariate Statistics. 6th edition. Pearson, London, United Kingdom.

Vincent, S.E., A. Herrel, and D.J. Irschick. 2004. Sexual dimorphism in head shape and diet in the Cottonmouth snake (Agkistrodon piscivorus). Journal of Zoology 264: 53-59.

Wang, S., H.C. Lin, and M.C. Tu. 2003. Skewed sex ratio of the Chinese Green Tree Viper, Trimeresurus stejnegeri stejnegeri, at Tsaochiao, Taiwan. Zoological Studies 42: 379-379. 